\title{
Influence of Surface Roughness on the Transfer Film Formation and Frictional Behavior of TiC/a-C Nanocomposite Coatings
}

\author{
K. P. Shaha $\cdot$ Y. T. Pei - D. Martinez-Martinez • \\ J. Th. M. De Hosson
}

Received: 7 July 2010/ Accepted: 20 August 2010/Published online: 5 September 2010

(C) The Author(s) 2010. This article is published with open access at Springerlink.com

\begin{abstract}
Influence of surface roughness on the friction of TiC/a-C nanocomposite coatings while sliding against bearing steel balls in humid air was examined by detailed analyses of the wear surfaces and the wear scar on the ball counterparts by atomic force microscopy, optical, and confocal microscopy. It was observed that the surface roughness of the coatings essentially determines the wear behavior of the ball counterpart, which consequently influences the transfer film formation. A rough coating causes abrasive wear of the steel ball during the running-in period, which impedes the formation of a stable transfer film and leads to higher values of coefficient of friction (CoF). Moreover, the CoF does not show a decreasing trend after the running-in period, although the roughness of the coating was greatly reduced. Replacing the worn ball with a new one after the running-in period yields lower CoF values similar to that observed for a smooth coating. In both of the cases, no wear of the steel ball occurs and a stable transfer film forms and effectively covers the contact area. The influence of the wear debris on the formation of the transfer film is also discussed.
\end{abstract}

Keywords Roughness · Friction · Hardness ·

Nanocomposite coating

For metals, in most cases, initial surface textures are rapidly destroyed as soon as wear starts. However, under low

K. P. Shaha · Y. T. Pei · D. Martinez-Martinez .

J. Th. M. De Hosson ( $\square)$

Department of Applied Physics, Materials innovation institute

M2i, University of Groningen, Nijenborgh 4, 9747 AG

Groningen, The Netherlands

e-mail: j.t.m.de.hosson@rug.nl loading conditions and/or for materials with a high hardness, wear rate is low and thus the initial surface roughness may play an important role in tribology. This is usually the case of hard protective coatings [1]. Diamond like carbon (DLC) based coatings are of significant interest because of their unique combination of high hardness, chemical inertness, high wear resistance, and low coefficient of friction (CoF) against many counterface materials [2]. Incorporation of nanosized carbide particles (TiC, WC, $\mathrm{TaC}$ ) is expected to further improve their properties [3-5]. It is known that the frictional behavior of DLC-based coatings is affected by their chemical structure $\left(\mathrm{sp}^{2} / \mathrm{sp}^{3}\right.$ content), the content of other alloying elements and the extent of chemical and physical interactions with the surrounding environment [6]. The low friction of these coatings has been mainly attributed to the formation of a transfer film on the sliding surfaces of the counterface materials. The transfer film is believed to be formed by a friction-induced phase transformation of surface layer of DLC [7], and is mainly composed of amorphous graphitelike carbon that isolates the counterface material. As a result, sliding occurs mainly between the transfer film and the DLC coating, yielding low friction [8]. The presence of small amount of metal from the coating and its oxides as well as the iron oxides (due to oxidation of iron from the steel ball counterpart) in the transfer film in the case of the metal containing DLC are reported $[4,5,9]$. Also the presence of metal carbide (TiC) nano-crystallites, at the sliding surfaces, enhances the surface graphitization of the DLC matrix and promote formation of transfer film [3]. The density and chemical nature of the transfer film largely influence the $\mathrm{CoF}$.

The transfer film formation is affected by the environment, contact pressure, and sliding velocity [10-12]. The surface roughness of DLC coatings may also influence the 
transfer film formation. The substrate surface texture influences the frictional behavior of these coatings where generally coatings deposited on polished substrates are usually better [13]. In general, it is believed that a highsurface roughness yields major frictional and wear losses mainly during the running-in period [6]. However, the surface roughness may also influence the overall frictional behavior of these coatings. This letter describes a study of the tribological behavior of TiC/a-C nanocomposite coatings sliding against $100 \mathrm{Cr} 6$ steel ball in humid air, with particular emphasis on the effect of the surface roughness of $\mathrm{TiC} / \mathrm{a}-\mathrm{C}$ nanocomposite coatings on the frictional behavior and especially on the formation of transfer film. It is shown that frictional behavior was strongly influenced by the surface roughness rather than the coating material itself and was mainly dependent on the transfer film formation during sliding.

TiC/a-C nanocomposite coatings were deposited on smooth Si-wafer by simultaneous DC sputtering of Ti and pulsed-DC sputtering of graphite targets at $100 \mathrm{kHz}$ pulse frequency in an argon atmosphere. Recently, we have reported that the surface roughness of these coatings increases with increase in deposition time [14]. Thus, TiC/a-C nanocomposite coatings having similar chemical composition and chemical structure but various surface RMS roughness viz. $1.5 \pm 0.03,4.0 \pm 0.09,6.0 \pm 0.1 \mathrm{~nm}$ were obtained by varying the deposition time viz. 30,60 and $90 \mathrm{~min}$, respectively. The cross sectional scanning electron micrographs of these coatings revealed that the smooth coating with $1.5 \mathrm{~nm}$ roughness exhibits weak columnar structure (column diameter $\sim 55 \mathrm{~nm}$ ) whereas $6 \mathrm{~nm}$ rough coating exhibits strong columnar structure (column diameter $\sim 170 \mathrm{~nm}$ ) [14]. However, no cracks were observed on the wear tracks, which suggest that during sliding no rupture was happening at the column boundaries. Thus, the frictional behavior was not affected by the columnar features as discussed later in detail. The hardness and modulus of these coatings was 17 and $175 \mathrm{GPa}$, respectively. The surface roughness was measured by atomic force microscopy. The tribotests on these coatings were performed using a CSM tribometer, with a ball-on-disk configuration, against $\varnothing 6 \mathrm{~mm} 100 \mathrm{Cr} 6$ ball at a sliding speed of $10 \mathrm{~cm} / \mathrm{s}$ and normal load of $5 \mathrm{~N}$ and at room temperature $\left(20-23{ }^{\circ} \mathrm{C}\right)$ and constant relative humidity of $50 \%$. The hardness of the steel ball was $7 \mathrm{GPa}$. Optical and confocal microscopy was used to characterize the transfer film formed on the steel ball after the tribotest. The thickness of the transfer film was measured on three-dimensional images $(512 \times 512$ pixels $)$ of the wear scar on the steel ball, captured by a Nanofocus ${ }^{\circledR}$ confocal microscope after ultrasonically removing the wear debris. The $\mathrm{WSxM}^{\circledR}$ 4.0 Develop10.2 free software was used to select the pixels having transfer film on the confocal micrograph. The average and maximum thickness of the transfer film was then calculated by considering the $z$ values all these pixels.

Figure 1 shows the friction coefficient dependence on the surface roughness of the $\mathrm{TiC} / \mathrm{a}-\mathrm{C}$ nanocomposite coatings sliding against $100 \mathrm{Cr} 6$ steel ball. The $\mathrm{CoF}$ increases with increasing the surface roughness of these coatings. The coating of $6 \mathrm{~nm}$ roughness gives a CoF of 0.18 , being twice as much as that observed for the smooth coating with $1.5 \mathrm{~nm}$ surface roughness. This clearly reveals that the roughness strongly influences the frictional behavior of these coatings.

In the case of smooth coating, a quick drop in the $\mathrm{CoF}$ from an initially high value of about 0.23 at the beginning of sliding to 0.09 was observed as seen in Fig. 2a. This behavior was attributed to the quick formation of a transfer film on the ball counterpart, which facilitates interfacial sliding between the transfer film and the coating, rather than between the surfaces of the steel ball and the coating. Figure $2 \mathrm{c}$ shows a transfer film formed on steel ball after the tribotest, which covered almost $90 \%$ of the contact area. The average thickness of transfer film was $2.2 \mu \mathrm{m}$ (maximum up to $3.5 \mu \mathrm{m}$ ). The wear scar diameter was about $95 \mu \mathrm{m}$, which indicates that a little wear [15] of the steel ball occurred and the surface of the steel ball remained relative smooth. Simultaneous wear of the coatings also occurred and the rms roughness of the wear track evolved from the initial value of $1.5 \mathrm{~nm}$ to $0.48 \pm 0.01 \mathrm{~nm}$ at the end of 10,000 laps. Thus, the contact during most of the sliding occurred between two smooth sliding surfaces. Under these conditions, a stable transfer film formed and covered almost the entire contact area, leading to low CoF.

In the case of rough coating, a considerable increase in CoF up to 0.27 was observed during the running-in period and then it gradually decreased and reached to a steady-

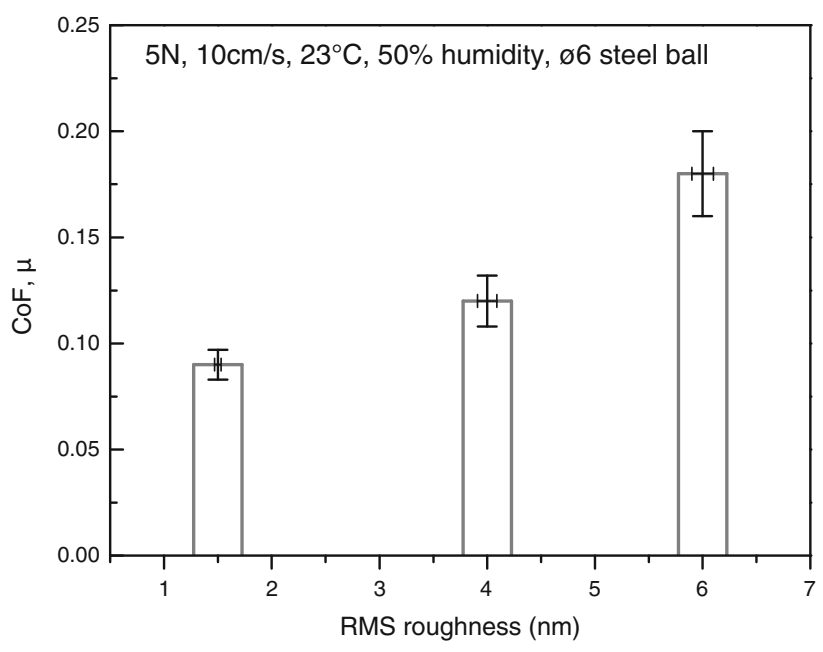

Fig. $1 \mathrm{CoF}$ versus the initial surface roughness of TiC/a-C nanocomposite coatings sliding against $\varnothing 6 \mathrm{~mm} 100 \mathrm{Cr} 6$ steel ball under the sliding conditions indicated 
Fig. 2 a Friction characteristics of bearing steel ball sliding against the TiC/a-C coatings having various surface roughness as indicated together with sliding against the polished surface (having rms roughness $1.9 \mathrm{~nm}$ ) of the rough coating obtained after sliding 1,500 laps. The rms roughness (in $\mathrm{nm}$ ) of the wear tracks on the coatings at the corresponding laps is indicated in round brackets. Optical micrographs showing the wear scar of $\varnothing 6 \mathrm{~mm} 100 \mathrm{Cr} 6$ steel balls after the running-in period against the rough nanocomposite coating (b), after 10,000 laps sliding against the smooth coating (c); against the polished surface with (d) and without wear debris (e); and against the rough coating (f). The sliding direction of the balls was from right to left
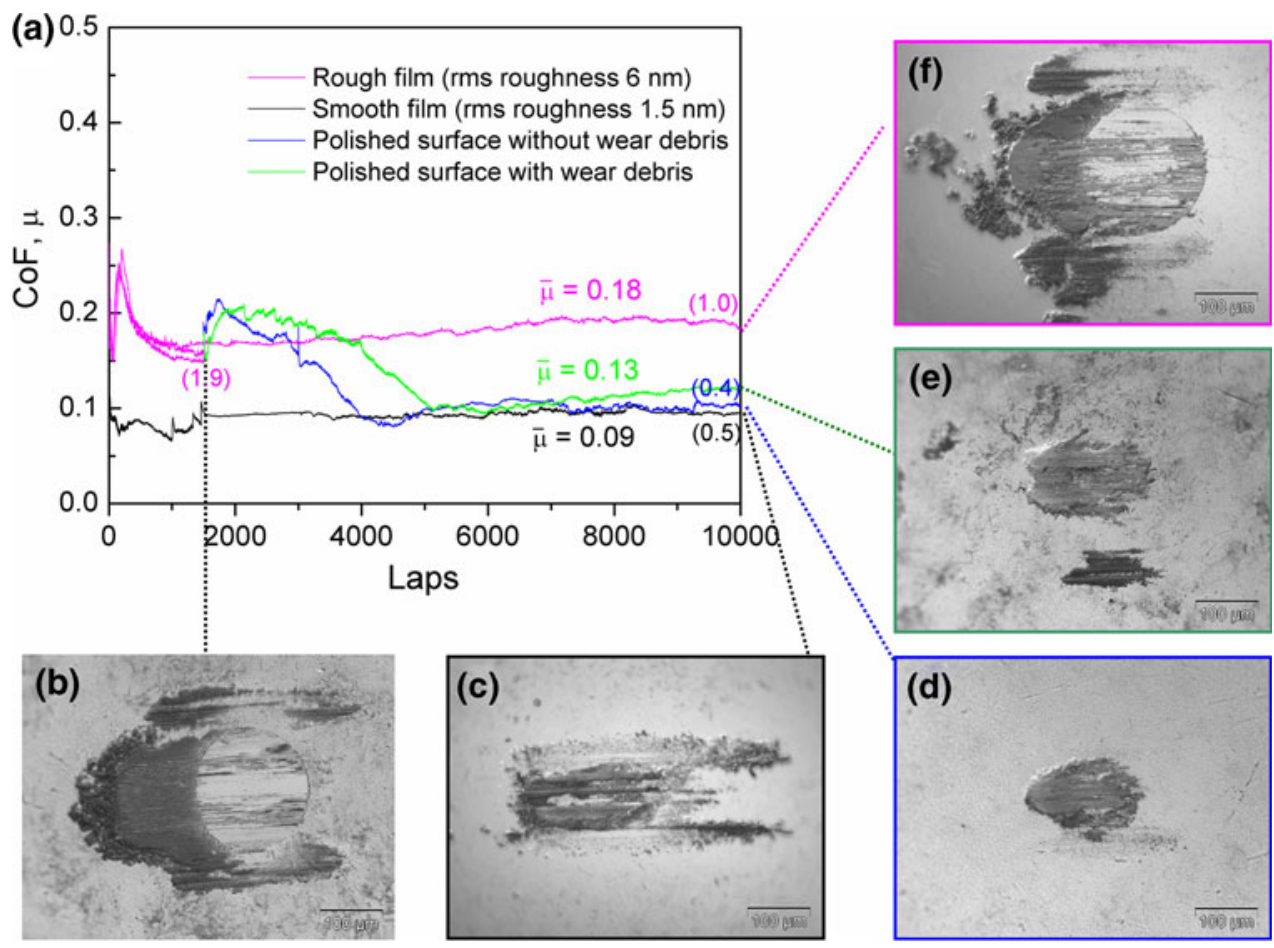

(d) state value of 0.18 . A significant wear of the steel ball was occurred during the running-in period since dense and long scratches, parallel to sliding direction, were observed on the wear scar as seen in Fig. 2b, together with a large amount of wear debris accumulated in the front. This suggests that during the initial stage of sliding, a high level of mechanical interlocking between the surface asperities takes place and leads to high friction and wear. Also, the maximum contact pressures are significantly higher for rough surfaces and are present at the surface asperities [16, 17]. It is concluded that, due to high contact pressures the sharp and hard asperities of the rough coating cause considerable abrasive wear of the ball mainly by plowing mechanism. Optical micrographs of the wear scar on the steel ball after 10,000 laps, as shown in Fig. 2f, revealed that a significant amount of material was transferred from the coating to the ball surface. It seems that, at the beginning of the formation of the transfer film, wear material was mainly accumulated in front of the sliding ball and later the transfer film covered the main part of the load-bearing contact area. However, the transfer film was rather thin and unevenly distributed and covered only about $30 \%$ of the contact area. The average thickness of the transfer film was $0.8 \mu \mathrm{m}$ (maximum up to $1.5 \mu \mathrm{m}$ ). The wear scar was rough and was about $220 \mu \mathrm{m}$ in diameter, only slightly larger than that formed after the running-in period $(\sim 200 \mu \mathrm{m})$, which indicates that wear of the ball mainly occurred during the running-in period. The removal of surface asperities of the rough coating reduces the maximum contact pressure and resulted in less wear of the ball after the running-in period. This is consistent with the observation made by Harries and Weiner [18] where they have shown that abrasiveness of the coating decreases with increasing number of the laps and the wear rate of the steel ball decrease. The wear rates of the steel ball and the coating were $1.82 \times 10^{-8}$ and $2.38 \times 10^{-8} \mathrm{~mm}^{3} / \mathrm{N} \mathrm{m}$, respectively. Thus, the volume of worn material from the steel ball was lower than that of the coating. The wear of the steel ball occured mainly during the running-in period since the wear rate at 1,500 laps was equal to $6.94 \times$ $10^{-8} \mathrm{~mm}^{3} / \mathrm{N} \mathrm{m}$ which further reduced to $6.2 \times 10^{-12}$ $\mathrm{mm}^{3} / \mathrm{N} \mathrm{m}$ measured at the end of 10,000 laps. The worn material from the steel ball was mainly accumulated at the front and on the sides of the wear scar as seen in Fig. 2b, f. However, the wear debris from steel ball may oxidize to form metal oxides and incorporated into the transfer film and contribute to increase in CoF [4]. The rms roughness of the wear track was reduced from initial $6 \mathrm{~nm}$ to $\sim 1 \mathrm{~nm}$ after 10,000 laps, relatively rougher than that on the smooth coating. This indicates that the sliding occurred between two comparatively rough surfaces. While sliding under such contact conditions, the transfer film became unstable due to frequent break down and failed to cover the majority of the contact area leading to high CoF. It is important to note that after the running-in period, the $\mathrm{CoF}$ did not show a decreasing trend but remained stable at a high value of 0.18 . This clearly shows that the high surface roughness not only gives a high $\mathrm{CoF}$ during the running-in period but also governs the overall frictional behavior of these coatings with a high steady-state CoF. Thus, the 
surface roughness of the coating mainly determines the nature of sliding surface of the steel ball where rough coatings yield rough and large contact area that further hinders the formation of a stable transfer film and leads to a high CoF.

In order to comprehend the effect of surface roughness, an initial tribotest for 1,500 laps was performed to polish out the surface asperities of the rough $\mathrm{TiC} / \mathrm{a}-\mathrm{C}$ coating. It was observed that the depth of the wear track on the coating was less than $20 \mathrm{~nm}$ as measured by confocal microscopy. Thus, the thickness of the coating and hence the columnar structure remained almost the same, but rather a significant decrease in the surface roughness of the coating from an initial value of $6 \mathrm{~nm}$ to $1.9 \pm 0.1 \mathrm{~nm}$. This polished surface exhibits plateaux and sharp grooves. After removing the wear debris from the wear track by ultrasonic cleaning, a tribotest was performed with a new steel ball on this polished surface. This yielded a steady-state $\mathrm{CoF}$ of 0.10 . For the same coating exhibiting strong columnar features, as the surface roughness decreased from 6 to $1.9 \mathrm{~nm}$, the steady-state CoF was reduced from 0.18 to 0.1 . Also, the values of steady-state $\mathrm{CoF}$, as seen in Fig. 2a, for the polished surface exhibiting strong columnar structure and the smooth coating exhibiting comparatively weaker columnar structure are comparable, as seen in Fig. 2a. This further demonstrates that the $\mathrm{CoF}$ was largely affected by the surface roughness of the $\mathrm{TiC} / \mathrm{a}-\mathrm{C}$ coatings and independent of the columnar microstructure if no cracks occurred along the column boundaries. The thickness of the transfer film was also comparable to that observed against the smooth coating. However, in the case of polished surface, the formation of transfer film was a rather sluggish process since the steady-state $\mathrm{CoF}$ was reached only after 2,500 laps, in comparison to the smooth coating where a transfer film formed within less than 30 laps. This indicates that the wear of initial small surface asperities of the smooth coating facilitate the transfer film formation. The wear scar on the steel ball shown in Fig. 2d revealed that the transfer film completely covered the contact area. No noticeable wear of the ball was observed. On the other hand, the surface roughness of the wear track was further reduced from 1.9 to $0.4 \pm 0.1 \mathrm{~nm}$. Furthermore, while sliding against this $0.4 \mathrm{~nm}$ smooth polished surface of the rough coating with a new steel ball the steady-state $\mathrm{CoF}$ (not shown) was equal to 0.1. This suggests that below a certain roughness, $1.5 \mathrm{~nm}$ in case of these coatings, the friction was not influenced by the surface roughness.

In order to understand the role of wear debris, another tribotest was performed with a new steel ball on a polished surface (rms roughness $1.9 \mathrm{~nm}$ ) of the rough coating but without removing the wear debris. The steady-state $\mathrm{CoF}$ was 0.13 in this case, as shown in Fig. 2a. It is noteworthy that more laps were needed to reach the steady-state $\mathrm{CoF}$ as compared to those required in the absence of wear debris on the wear track. This shows that the presence of hard wear debris retards the formation of the transfer film, likely serving as three body abrasive to break down the tender transfer film as indicated by the dense fluctuations in the CoF curve at the beginning of test. The wear debris may re-circulate in and out of the contact during the running-in period as observed by Scharf and Singer [19]. The wear debris were collected by the steel ball as shown in Fig. 2e and also was accumulated on both sides of the wear track, indicating that they were eventually removed from the sliding contact.

The last issue of this work was to reveal the effect of surface roughness on an existing transfer film. A transfer film was initially created on a steel ball by sliding it against the smooth coating for 5,000 laps, and then the ball with transfer film was further slid for 10,000 laps against the rough coating as shown in Fig. 3a. After a significant increase during the running-in period, similar to that
Fig. 3 a Friction characteristics of steel ball having initial transfer film (created by sliding against smooth coating; $0-5,000$ laps indicated by black color), sliding against the rough TiC/a-C nanocomposite coating (5000-15,000 laps; indicated by orange color); Optical micrographs of the steel ball having initial transfer film b before and $\mathbf{c}$ after sliding against the rough coating, respectively (Color figure online)

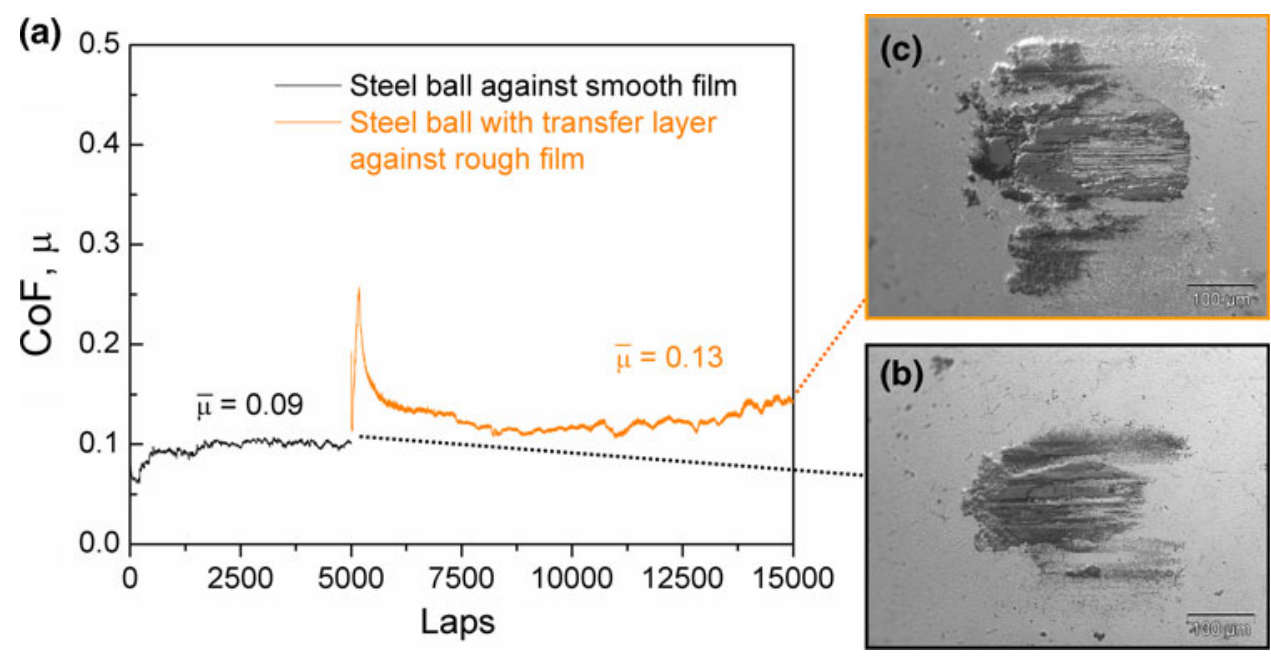


observed in Fig. 2a for rough coating, the CoF gradually reduced to about 0.13 . Abrasive wear during the running-in period yielded an increase in the size of wear scar from $\sim 100 \mu \mathrm{m}$ to $\sim 175 \mu \mathrm{m}$ as shown in Fig. $3 \mathrm{~b}$, c, respectively. The CoF was lower than that observed for a steel ball without having initial transfer film. It indicates that the existing transfer film was not completely removed from the steel ball during the running-in period. Also, the wear scar on the ball having initial transfer film was smaller $(\sim 175 \mu \mathrm{m})$ than that observed on steel ball $(\sim 230 \mu \mathrm{m})$ without having initial transfer film. This observation revealed that the initial transfer film protected the steel ball to some extent during the running-in period. It was noted that the CoF was not reaching to a steady state but rather was fluctuating and showed increasing trend at the end of the test as seen in Fig. 3a. This shows that the rough and large sliding surface of the steel ball, caused during running-in period, destabilizes the transfer film formation and eventually the transfer film fails to cover fully the entire contact area leading to increase in $\mathrm{CoF}$.

In conclusion, we have studied the effect of surface roughness on the formation of transfer film and frictional characteristics of TiC/a-C nanocomposite coatings of the same chemical composition and different columnar structure, sliding against bearing steel ball. Higher surface roughness exhibited a higher steady-state $\mathrm{CoF}$, which was independent of the columnar microstructure due to excellent toughness of these coatings. The friction characteristics were controlled to a large extent by the transfer film coverage of the contact area on the steel ball. A rougher $\mathrm{TiC} / \mathrm{a}-\mathrm{C}$ coating yielded a rougher and larger contact area on steel ball due to abrasive wear that obstructs the formation of effective transfer film. The wear debris also retarded the formation of transfer film. In contrast, formation of a stable transfer film with maximum coverage of the contact area while sliding against smooth surfaces yields a low CoF. Thus, smooth coatings are critical for obtaining low CoF.

This research was carried out under the project no. MC7.06246 in the framework of the research program of the Materials innovation institute M2i (www.M2i.nl), Delft, the Netherlands. The authors acknowledge financial support from the M2i.

Open Access This article is distributed under the terms of the Creative Commons Attribution Noncommercial License which permits any noncommercial use, distribution, and reproduction in any medium, provided the original author(s) and source are credited.

\section{References}

1. Jiang, J., Arnell, R.D.: The effect of substrate surface roughness on the wear of DLC coatings. Wear 239, 1-9 (2000)

2. Robertson, J.: Diamond-like amorphous carbon. Mater. Sci. Eng. R37, 129-281 (2002)

3. Pei, Y.T., Galvan, D., De Hosson, J.Th.M., Cavaleiro, A.: Nanostructured TiC/a-C coatings for low friction and wear resistant applications. Surf. Coat. Technol. 198, 44-50 (2005)

4. Voevodin, A.A., O'Neill, J.P., Zabinski, J.S.: Tribological performance and tribochemistry of nanocrystalline WC/amorphous diamond-like carbon composites. Thin Solid Films 342, 194-200 (1999)

5. Nilsson, D., Svahn, F., Wiklund, U., Hogmark., S.: Low-friction carbon-rich carbide coatings deposited by co-sputtering. Wear 254, 1084-1091 (2003)

6. Erdemir, A., Donnet, C.: Tribology of diamond-like carbon films: recent progress and future prospects. J. Phys. D Appl. Phys. 39, R311-R327 (2006)

7. Voevodin, A.A., Phelps, A.W., Zabinski, J.S., Donley, M.S.: Friction induced phase transformation of pulsed laser deposited diamond-like carbon. Diam. Relat. Mater. 5, 1264-1269 (1996)

8. Erdemir, A., Bindal, C., Fenske, G.R., Zuiker, C., Wilbur, P.: Characterization of transfer layers forming on surfaces sliding against diamond-like carbon. Surf. Coat. Tech. 86, 692-697 (1996)

9. Sánchez-Lopez, J.C., Martinez-Martinez, D., Lopez-Cartes, C., Fernandez, A.: Surf. Coat. Technol. 202, 4011-4018 (2008)

10. Pei, Y.T., Galvan, D., De Hosson, J.Th.M.: Nanostructure and properties of TiC/a-C:H composite coatings. Acta Mater. 53, 4505-4521 (2005)

11. Pei, Y.T., Huizenga, P., Galvan, D., De Hosson, J.Th.M.: Breakdown of the coulomb friction law in TiC/a-C:H nanocomposite coatings. J. Appl. Phys. 100, 114309-1-114309-9 (2006)

12. Grill, A.: Tribology of diamondlike carbon and related materials: an updated review. Surf. Coat. Tech. 94, 507-513 (1997)

13. Svahn, F., Rudolphi, A.K., Wallen, E.: The influence of surface roughness on friction and wear of machine element coatings. Wear 254, 1092-1098 (2003)

14. Shaha, K.P., Pei, Y.T., Chen, C.Q., Turkin, A.A., Vainshtein, D.I., De Hosson, J.Th.M.: On the dynamic roughening transition in nanocomposite thin film growth. Appl. Phys. Lett. 95, 2231021-223102-3 (2009)

15. Shaha, K.P., Pei, Y.T., Martinez-Martinez, D., De Hosson, J.Th.M.: Influence of hardness and roughness on the tribological properties of TiC/a-C nanocomposite films. Surf. Coat. Tech. (under review)

16. Sayles, R.S.: Basic principles of rough surface contact analysis using numerical methods. Tribol. Int. 29, 639-650 (1996)

17. Stachowiak, G.W., Batchelor, A.W.: Engineering Tribology. Butterworth-Heinemann, Boston (1993)

18. Harris, S.J., Weiner, A.M.: Scaling relationships for the abrasion of steel by diamond like carbon coatings. Wear 223, 31-36 (1998)

19. Scharf, T.W., Singer, I.L.: Role of transfer film on the friction and wear of metal carbide reinforced amorphous carbon coatings during run-in. Tribol. Lett. 36, 43-45 (2009) 